Gunn Elisabeth Birkelund

\title{
Rational Laziness - When Time Is Limited, Supply Abundant, and Decisions Have to Be Made*
}

Abstract: This paper expands the model of rational action by introducing a new concept. rational laziness, to better understand actors' decision making. In addition to rational information processing, human beings often rely on automatic and non-cognitive mental capacities, and I use the term mental laziness to account for information processing based on these capacities. When time is limited, supply abundant, and decisions have to be made, mental laziness might be a rational decision device. Actors' choice of rational-calculating or automatic-spontaneous mental decision devices is contingent on their locations within an opportunity structure. The empirical case studied is employers' hiring processes, and employers' activation of these action generating mechanisms are expected to cause discrimination of job applicants categorized as out-groups members.

\section{Introduction}

In Foundations of Social Theory (1990) James Coleman argues sociology's main topics of investigation are complex social structures and processes. Sociology therefore would benefit by applying simple models of individual action, such as a modified version of the rational choice model applied in economics. In this paper I build on Coleman's intuition (see also Hedström 2005), yet I expand the model of individual action to also include action generating mechanisms from cognitive science and social psychology. In particular, I build on research showing that human beings often rely on automatic and non-cognitive mental capacities, and I use the term mental laziness to account for information processing that relies on these processes. There is no moral disparagement associated with the concept of laziness: in fact, relying on spontaneous automatic information processing in decision making might be cost/benefit efficient since these mental processes might help actors reduce the time and energy invested. If this is the case, a vital question then would be under what circumstances drawing on automatic non-

\footnotetext{
* 1 would like to thank Ferdinand A. Mohn, Kristian Heggeb $\varnothing$, Lise Kjølsrød, Torkild H. Lyngstad, Jon Rogstad, and John Eriksen for inspiring discussions on some of the items in this paper. I am also very grateful to the reviewers and the editors for valuable comments. The argument advanced here, and possible mistakes and misunderstandings, are however my own responsibility.
} 
cognitive capacities instead of cognitive considerations might be more efficient. To answer this question we need to link the actor to his/her opportunity structure and delineate what these circumstances might be.

In general we may assume an actor's preferences will partly depend on his/her definition of the social situation and the social role or position he/she occupies. Thus. it makes sense for sociologists to contextualize actors and their preferences (Birkelund 2010). An actor in the role of an employer represents a business firm (or a public work organization). In a competitive product market the hiring decisions of employers are vital for the firm's future productivity, and a wrong decision would imply high costs to their firm.

I will make an attempt to develop our understanding of the first phase of the hiring process by discussing how we might specify the social mechanisms involved in employers' decision making. According to cognitive psychologists automatic mental processes occur all the time, and these processes are helpful for human beings. ${ }^{1}$ Relying on automatic mental processes may be productive if it makes actors more efficient. The rational laziness argument rests on two premises, volume and time limitations, both related to the opportunity structure. First, the number of job applications is an indicator of employers' attractiveness and thus, their location in the labor market. Second, in modern working life, time is limited, and for employers receiving many job applications, the first screening needs to be fast. ${ }^{2}$ Thus, the opportunity structure is important for actors' choice of decision device.

My argument might be regarded as a special case of the model of frame selection developed by Esser and Kroneberg. ${ }^{3}$ This model proposes an integrative theory of action, building on concepts such as frame, scripts and variable rationality. The model is based on insights from cognitive science, identifying two distinct systems of information processing: a reflective-calculating mode ( $r$ mode) and an automatic-spontaneous mode (as-mode) (Kroneberg 2014, 100). The authors have suggested a second-order subjective expected utility heuristic which (unconsciously) guides actors to consider as-mode or rc-mode as most useful for a particular situation. My argument is related to this framework, with the precision that actors' definition of their situation - and thus their choice of frames and scripts - are structurally bounded by their market situation. When hiring new employees I assume employers start by a consciousness (rc-mode) evaluation of available opportunities before their choice of decision mode for the information processing.

The perspective advanced in this paper locates the actor within an opportunity structure, and their choice of decision device is constrained by their position within this structure. The action generating mechanisms discussed here are contingent on actors' perception of their opportunity structure (Petersen 2009) and draws in particular on actor and structure assumptions associated

\footnotetext{
1 Other related concepts are system 1 thinking (Kahneman 2011), mental butlers (Bargh/Chartrand 1999), and cognitive misers (Fiske/Taylor 1984).

2 Exceptions will be when an employer or hiring firm looks for a person of particular competence, like evaluating applicants for top positions. Then I would presume all qualified applicants were considered carefully.

isee Esser 2001.
} 
with the situational and action-formation mechanisms; i.e., the macro-to micro and then micro-to-micro links in the Coleman diagram (Coleman 1990: Hedström/Swedberg 1998: Hernes 1998: Manzo 2014).

Analytically the concept of rational laziness implies a modification of a rational action model, and adds to the existing theories of action. such as the DBO scheme (Elster 1985: 2007: Hedström 2005). Whereas taste-based discrimination $^{4}$ and statistical discrimination can be classified as rational-conscious ( $r c$ mode) information processing, decisions based on rational laziness also includes the automatic-spontaneous mode (as-mode).

\section{Empirical Background}

We know that employers often discriminate against minorities when they hire new employees. Randomized field experiments, acknowledged as the best way to measure discrimination since these experiments isolate the effect of minority/majority status, have documented beyond doubt that discrimination occurs (OECD 2013). The overall level of discrimination differs across countries and over time, with call-back rates varying between 1.1 and 2.5 (OECD 2013, Table 4.1). A call-back rate of 1.5 implies that on average, a minority applicant needs to send 15 applications before he/she can expect a call-back from an employer whereas a majority applicant only needs to send 10 applications before he/she can expect a call-back from an employer. These studies also document that the world is not black and white: many employers do not discriminate, an often neglected fact when we talk about discrimination.

Two projects on ethnic labor market discrimination have documented that employers in Norway do not differentiate between job applications from immigrants and job applications from native born children of immigrants, that is, between first and second generation immigrants (Midtbøen/Rogstad 2012; Birkelund et al. 2014). We interviewed a sample of employers, asking them about the labor market opportunities for second generation immigrants, and they replied they would hope the opportunities were good for immigrants, but they also commented that hiring them might be problematic due to language problems and cultural differences. We then specified again that we were interested in their opinions about the future opportunities for the second generation immigrants, who are born and raised in Norway, speak Norwegian and have attended domestic schools. And again the employers' answers would rapidly slide sideways, from talking about second generation immigrants to talking about immigrants in general.

To me this was a puzzle. Why did these employers not differentiate between first and second generation immigrants? How can we understand this apparent lack of interest in and willingness to differentiate between the new citizens in our society? An obvious first answer would be they are prejudiced against 'foreigners', which also comprise the native born children of immigrants. However, as time passed on, I have become more convinced that this could not be the whole

\footnotetext{
${ }^{4}$ In the model of taste-based discrimination tastes are exogenously given.
} 
story. In order to understand employers' reactions, we need to be more specific about the different stages involved in a hiring process. and try to understand the decision devices employers are likely to draw on when deciding who to call in for an interview.

When evaluating job applicants, one of the first things employers notice is the names of the applicants. Most immigrants do not change their names upon arrival in their new country of residence. To the native population, many of these names sound foreign. The immigrants usually also give 'foreign' names to their native born children. If employers are prejudiced and thus have a taste against foreigners in general they may discriminate against job applicants with foreign names (taste-based discrimination), independent of which generation they belong to. Another theory of discrimination (statistical discrimination) would emphasize other aspects, such as lack of information about the potential productivity of job applicants. If employers are sensitive to names we would nevertheless expect them to notice that native born descendants of immigrants have domestic education. This would distinguish them positively from applicants with foreign education, since employers would be more likely to think they lack sufficient information on the quality and content of foreign educational institutions.

Both the theory of taste-based discrimination and the theory of statistical discrimination assume that employers are rational actors, implying they calculate the costs and benefits associated with their preferences, and act consistently in choosing the self-determined best choice of action to maximize their utility function. If we move from the rational choice perspectives to a socialpsychological perspective on discrimination, we would recognize that employers might be cognitively unaware of the fact that they discriminate. If they automatically categorize job applicants with foreign names as out-group members, they may drop them, also second generation, from further consideration. In other words: there are competing theories of discrimination, which might explain why employers discriminate. But it is not clear under what circumstances they are most fruitful. Our understanding of discrimination would benefit if we could be more specific in terms of delineating carefully the decision making process and the impact of contextual factors (here: in particular the labor market) on employers' decisions.

This paper is organized in the following way: I first discuss how discrimination might be related to in-/out-group categorization. Then, I discuss the concept of 'bounded rationality', building on Herbert Simon's 1955 article. Next I try to integrate the notion of bounded rationality and cognitive 'laziness'. In the last part of the paper I move from abstract theories to more specific contexts, in particular related to employers' decision making. I will not be able to adjudicate empirically between these models but I report briefly from two empirical studies of discrimination, which might serve as illustrations of my main argument. And my main argument is that rational laziness should be regarded as one of several decision devices. 


\section{Discrimination Based on Stereotyping, Prejudges, In-/out-group Categorization}

According to social psychologists, everyone must categorize, in order to function. The complexity of reality overwhelms the human mind, thus, a number of simplifying strategies are needed. As demonstrated in laboratory experiments our cognitive capacities are limited. Participants are unable to solve a complicated task and negotiate on chocolate distribution in the group at the same time, to take one example. ${ }^{5}$ Thus, psychological researchers have argued that unconscious processes are vital and helpful, not only for our inner selves, identities, thoughts and dreams, but also as movers for action and interaction with other human beings.

Summarizing social psychological research on stereotyping, prejudice, and discrimination, Fiske (2000) argues that Allport's classic study of the nature of prejudice documented the normality of individuals prejudging others: "People normally prejudge, form ingroups, and reject outgroups." (Fiske 2000, 303) This insight implies that stereotyping is normal. Several exponents for this perspective on discrimination have emphasized that human beings have survived due to our abilities of instant categorization and differentiation of friend from enemy. Fiske and Taylor (1984) used the term cognitive miser to explain shortcuts to category-based information, and argued that these processes are not guided by a wish - or motivation - to prejudge. It is common to relate human beings' ability to automatically categorize strangers into in-group or out-group to an evolutionary argument: people need to survive, and to do so, they need to belong to a group. Thus, definition of and loyalty to their in-group is a biological predisposition, and suspicion or even hostility towards out-groups is likely: "[... People identify and value their ingroup, thereby derogating the outgroup." (Fiske 2000, 303: see also Tajfel et al. 1971)

The question of how people classify newcomers as either belonging to their in-group or to an out-group is interesting. It takes only milliseconds for people to detect each other's (probable) gender, race, and age, and thereby quickly categorize in-group members. This automatic categorization also rapidly includes stereotyping of out-group members. People respond more positively to in-group members than to out-group members (Dovidio/Gaertner 2000), thus there is an in-group advantage which precedes out-group disadvantage. People are also reserving trust for their in-group, and cautious in trusting out-group members (Fiske 2000, 311). These decisions are non-cognitive: we are unaware that we automatically categorize strangers as members of our out-groups. Automatic categorization is associated with out-group skepticism, i.e. xenophobia, and/or in-group favoritism, i.e. homophily (Baragh/Chartrand 1999: Dovidio/Gaertner 2000; Gaertner/Dovidio 2005: Jost et al. 2009). Research in social psychology has also documented that human beings normally use efficient heuristics. When processing large volumes of information, human beings have a tendency to take cognitive short-cuts to category-based information (Fiske 2000). Applying effi-

\footnotetext{
5 See Baumeister et al. 1998 on self-control and self-regulation.
} 
cient heuristics is often the best way to arrive at sensible and reasonable decisions without wasting time. Thus. I would argue. in-/out-group categorization. and associated stereotypes. might influence our decisions more often when time is limited. supply abundant. and rapid decisions have to be made. Two mechanisms should be mentioned, related to each other, but not necessarily identical:

1. Homophily occurs when we favor in-group members. Discrimination based on homophily would imply that employers prefer members of his/her ingroup, even if better qualified job applicants are available.

2. Xenophobia occurs when we have negative attitudes towards individuals we classify as members of an out-group. Discrimination based on xenophobia would imply that employers automatically classify some job applicants as out-group members, who are thereafter dropped from further evaluation.

These automatic categorizations also imply stereotyping and attributing group characteristics to individuals in both groups. It is an open question if -and to what degree implicit biases might be overruled by cognitive reflection and reasoning. A study from the US shows that employers with positive experiences with black workers regard them as exceptions from their cultural stereotypes about black workers (Pager/Karafin 2009). Thus the authors argue that a Bayesian learning experience, where the actor updates his/her attitudes towards a group based on personal experience. does not occur: rather it seems, in-/out-group classifications are automatic and resistant to empirical adjustments and validation. This finding is not consistent with the economic theories of discrimination. Again. research on fundamental priming of stereotypes and in-/out-group categorization might explain why people do not update their stereotypes despite new information. ${ }^{6}$ The insight that all human beings are prejudiced. and sceptical towards individuals we categorize as out-group members, should imply high levels of discrimination, all else equal. But people's attitudes and cognitive biases are not necessarily transformed directly into behavior. and we lack specific knowledge about how our biases affect our behavior (Fiske 2000). Yet we may assume that employers who rely on automatic categorization processes in hiring processes might cause discrimination against individuals classified as out-group members. Jost et al. (2009) argue that bias related to implicit associations can predict "[...] socially and organizationally significant behavior. including employment" (Jost et al. 2009. 39). Thus, automatic categorization processes is of relevance in hiring processes.

To summarize: The perspectives discussed above are usually regarded as competing. yet it has been difficult to adjudicate empirically between them. The actor perspectives associated with these theories can be classified into two 'camps'. They either assume employers are rational actors, as in taste-based discrimination and statistical discrimination. Or. they assume employers' decision making is influenced by automatic categorizations and stereotypes. But what if

6 Laboratory experiments have documented the existence of fundamental priming effects; see for example research on status construction (Ridgeway 2006). and on "double standards" (Foschi 2000). 
these perspectives are not exclusive? In real life research we need to specify the different phases of the process we are trying to understand. The hiring process often comprises three stages: a screening process. where a large number of applications are reduced to a smaller number; a sorting process, where the most interesting candidates are scrutinized in more detail: and later, perhaps several stages later, a call-back to the most relevant candidates for a job interview (see, for instance Petersen/Saporta 2004). Perhaps employers draw on different decision devices in different phases of this process? To better understand employers' hiring decision process, we start with a market based model based on actors' limited rationality rather than an abstract model of global rationality.

\section{A Behavioral Model of Bounded Rationality}

60 years ago Herbert Simon published A Behavioral Model of Rational Choice (1955), which changed the way we understand rational choice and rational action. The abstract notion of 'economic man', he writes, is '[...] assumed to have knowledge of the relevant aspects of his environment which, if not complete, is at least impressively clear and voluminous. He is assumed also to have a well-organized and stable system of preferences, and a skill in computation that enables him to calculate, for the alternative courses of action that are available to him, which of these will permit him to reach the highest attainable point on his preference scale." (Simon 1955, 99) Thus, the classical model of economic man is certainly not a very realistic model of social action. Simon argued human beings are faced with both internal (psychological and mental capacities) and external constraints (related to the environment in which the actor is located). He therefore proposed a model of rational choice which more explicitly accounts for these constraints, and he introduced the concept of satisficing as a more realistic alternative to the maximization strategy of the economic man: given limited resources it makes sense, also in economic terms, to stop gathering more information about all possible alternatives when one has reached a satisfactory level. This means the actor would make a subjective judgement ${ }^{\top}$ of the present choice set, and then decide whether it makes sense (based on cost/benefit calculations and their degree of risk-averseness) to continue searching for new alternatives. ${ }^{8}$

One simplification related to the satisficing strategy is to assume that the 'pay-off' of individuals' decisions is not defined by a maximizing criterion (maximizing their utility function): rather, in markets, individuals often operate with a threshold price over which they are willing to make a deal. Another simplification is related to the processing of information. When individuals are unable to see all alternatives at once, they may relate to them in sequences. "In most global models of rational choice, all alternatives are evaluated before a choice is made. In actual human decision-making, alternatives are often examined se-

7 See Boudon 1989 for a discussion on subjective rationality.

8 A number of extensions have been developed, to define a psychology for economics that is more psychologically realistic than the rational choice model. For a good overview. see Kahneman's lecture for the Bank of Sweden Prize in Economic Sciences in Memory of Alfred Nobel (Kahneman 2003). 
quentially." Simon refers to a house market. where the seller is confronted with "[...] a sequence of pairs of triplets or n-tuplets of offers, and may have to decide whether to accept the highest of an n-tuple before the next n-tuple is received" (Simon 1955, 105). As we will discuss below, the hiring process often implies a sequencing of employer decisions, from addressing many to addressing few job applications. Third, contrary to the classical model of economic man, Simon's model allows us to compare apples and oranges. Whereas the classical theory assumes all pay-offs could be scaled along one dimension, Simon's model does not need this simplifying assumption. Rather, he expands his model to include a partial ordering of pay-offs, including also values that do not have a common denominator, as when an individual "[...] compares two jobs in terms of their salary, climate, pleasantness of work, prestige, etc." (Simon 1955, 109). This modification is also relevant in our case, if employers do not regard workers as substitutable for each other, for instance in terms of productivity, likelihood of absence, if the individual will fit in with other employees, etc. In these considerations, immigrant status might also be relevant.

Simon's model has been extended and developed, in particular into search theories to better understand decision making processes. Experiments covering settings that differ in the number of options available for the actors and in the complexity of those options find broad support for the satisficing model: most individuals search sequentially, and stop when they have reached a satisfactory level of utility (Chaplin, Dean/Martin 2011). Simon's actor has limited knowledge and abilities, but the model says nothing about non-cognitive aspects of the decision making process. To get at this, we next try to integrate the notion on bounded rationality with the literature on stereotyping and in/out-group classifications.

\section{From Abstract Theories to Contextualized Decision-making}

At the outset, the perspectives discussed above operate with abstract, contextfree actors. An empirical analysis of labor market discrimination would need to locate the actors (employers) within their firm and then specify the opportunity structure within which they operate. The most relevant structural location of employers (or their hiring managers) is their position in the labor market. If the labor market is tight the employers will receive few applications, in a slack labor market they will receive many applications. I.e. the labor market context matters to the volume and perhaps also the quality of the applications which employers receive when they advertise a vacant job. Given that employers usually work under time pressure, I would assume that in particular the volume of the task they are dealing with will influence their choice of decision devices.

The contextualization hypothesis is a market-based argument, which is in line with both taste-based discrimination, statistical discrimination and discrimination based on rational laziness: 
- Taste-based discrimination: With many applicants, the employer might screen the applications on the basis of his/her tastes. With few applicants. the employer might need to hire someone he/she does not like.

- The statistical discrimination model: With many applicants, the employer might screen on the basis of his/her perceived lack of information, riskaverseness and cost/benefit calculations. With few applicants, the employer might need to hire someone even though he/she would have wanted more relevant information about the candidate.

- Rational laziness: With many applicants, the employer might screen the applications on the basis of his/her automatic in-/out-group classifications. With few applicants, the employer would process all applications.

Thus, if there are many applicants, a rapid screening is rational. But the screening device differs: Becker's theory takes 'tastes' as exogenously given, whereas I refer to research in social psychology on non-cognitive stereotypes as the locus of these 'tastes'. Thus, rational laziness includes references to mental 'butlers', whereas the actor in economic theory is a black box in terms of mental activities, except for her/his cognitive ability to calculate, etc.

Statistical discrimination assumes a classic rational actor (or bounded rationality), and the screening device would be based on items that can be measured in cost/benefit analysis, such as the likelihood that an applicant will speak Norwegian, be a stable and productive worker, etc. The laziness argument implies resorting to tastes and preferences, based on non-cognitive decision devices: and I therefore think the argument advanced in this paper is more useful as an extension of the taste-based model of discrimination than the statistical discrimination model.

In a process of fast screening I would expect employers to pay attention to only a few individual characteristics for each applicant. Their names are an obvious candidate. Two recent studies are particularly relevant here. A Swedish study found that immigrants from Asian/African/Slavic countries who changed their surname to Swedish-sounding or neutral names made a substantial earnings increase (Arai/Skogman Thoursie 2009). This finding most likely also reflects a higher chance after a name change of being called to a job interview. Thus, names matters for job opportunities. A Dutch study examined discrimination against Arabic-named applicants in online job recruitment web pages (Blommaert et al. 2014). The authors were able to identity two phases of the initial recruitment process: employers first saw only short profiles of the applicants, including their names. After this, they then decided if they wanted to view applicants' complete résumês. The results provided strong evidence of namebased discrimination: résumés of Arabic-named applicants were requested less often, regardless of their education, gender, age, region, or sector. The authors concluded that discrimination based on prejudices and stereotypes arise in the screening phase of the hiring process. But their finding could also be a result of rational laziness. If employers considered they had enough applicants to choose from on these web pages it was not necessary for them to check all applicants. In 
both interpretations, however, we can presume the decision mechanism relied on in- and out-group categorizations and associated prejudices and/or stereotypes.

A Swedish study of the hiring process combined a field experiment with an Implicit Association test, undertaken by employers (Rooth 2010). Employers with stronger negative associations (1 standard deviation) against Arab-Muslim men had a 5 percent lower probability of calling male applicants with ArabMuslim names in for an interview. This finding is interesting for two reasons: the study demonstrates discrimination against an out-group, which seems linked to stereotypes; but the association is rather weak; only 5 percent difference. This study therefore reveals that implicit associations are relevant, yet these associations can definitely not be the whole story. In this case the main explanation for the high call-backs for minorities also among biased employers could be as simple as a tight labor market.

Let us consider the hiring process in more detail. The first question would be how many applicants are there? If there are few applications, the employer can look at them all. However, with many applications, the employer needs a screening/sorting device to arrive at a smaller number, which then will be scrutinized more carefully. Given time limitations, it is rational to use a simple screening/sorting device (Goldstein 2009). Empirically, two or three screening devices are likely to be applied at this stage. One decision device is meritocratic: the employer needs to sort out unqualified applicants. Second, if there are still many applicants, the employer is likely to be rationally lazy and drop candidates with names signaling foreign ethnicity they know little about (outgroups). The outcome would be discrimination against members of out-groups, who are not considered as candidates for the job - unless there are no other alternatives. Third, the employer might also, for groups he/she knows better, favor members of specific groups he/she likes (in-group members).

Note that I use the term out-groups here without specifying if employers classify all or some - individuals with immigrant backgrounds as out-group members, since we might expect this would vary between employers, dependent on their individual knowledge of immigrants. If there are few, or no, qualified job applicants from their preferred group, we would expect employers to take a closer look at applicants from other groups. Thus, employers are expected to apply automatic classification devices (out-group exclusion) only if they find enough relevant applications from their in-group (satisficing principle).

Cognitive laziness might guide the screening and sorting process. In the next step of the hiring process, we would expect the employer to take a more serious and considerate look at each application, and from this phase onwards, I would expect the usual notion of rationality (albeit bounded) to guide the decision making process. ${ }^{9}$

The argument is not that in-/out-group classifications only take place after rational considerations. As discussed above, in-/out-group classifications will instantly and automatically take place, independent of the actor's choice to

${ }^{9}$ However, later stages of the hiring process can also be influenced by different decision devices, as when the employer trusts his/her 'instincts', or gut feelings, when interviewing job applicants (Midtbøen/Rogstad 2012). 
try to overrule it. The argument is rather that non-cognitive biases are not necessarily transformed into behavior. Just as the satisficing strategy is only sensible to invoke if the task at hand is evaluated to be too large. given time and resources, we can argue the cognitive laziness strategy is only sensible to invoke if the task at hand is evaluated to be too large, given time and resources. Both decision devices are related to the opportunity structure: we only take the easy way out if we find it feasible and sensible to do so. The difference between the two strategies, which might seem negligent, could both theoretically and in practice be large. In the satisficing strategy, the employer would evaluate each individual case in a cognitively neutral manner, without prejudices, until he/she has found a satisfactory enough number of qualified candidates which then would be evaluated individually. The cognitive laziness strategy is different. In this model, the employer first applies a biased heuristic to sort out out-group applicants, so the task of evaluating each individual case, one at a time, is reduced to a smaller sub-set.

Another difference between the two concepts, satisficing and rational laziness, is related to the opportunity structure: the market structure differs in the two models. Simon's concept builds on a free market model, where employers regard actors (here job applicants) as substitutable, whereas the perspective developed here would take as its starting point that actors (job applicants) differ in nontrivial ways from each other. If an employer bases his/her judgment on rational laziness, resorting to in-/out-group classifications, the labor market is divided into sub-markets with un-substitutable applicants. These divisions are classified independent of the applicants' human capital, which breaks with the idea of a free market, underlying the rational choice perspectives (with either maximizing or satisficing as decision rules).

The flow chart in figure 1 illustrates an example of my argument. The relevant opportunity structure for employers is the labor market, and the number of applicants they receive for an advertised job depends on the economic fluctuations in the market and their firm's attractiveness in the labor market. The contextual/situational mechanism for the employers is therefore their location in the labor market. I would expect employers to draw on different decision devices at different stages of the hiring process, depending on their opportunities, as reflected in the available number of applicants and also their time schedules. If an employer receives many applications, he/she would need a quick screening device to reduce the number of applications for consideration. These first evaluations of the available work load I expect to take place in the rc-mode. Given an abundant number of applicants, I suggest employers allow themselves to be cognitively lazy (as-mode) and sort out applicants they categorize as members of out-groups. They may, for instance, drop all applicants with strange/foreign names. Using this decision device employers thereby reduce the pool of applicants before they proceed (in rc-mode) to evaluate the remaining applicants - a process identical to the cases where employers receive fewer applications. 


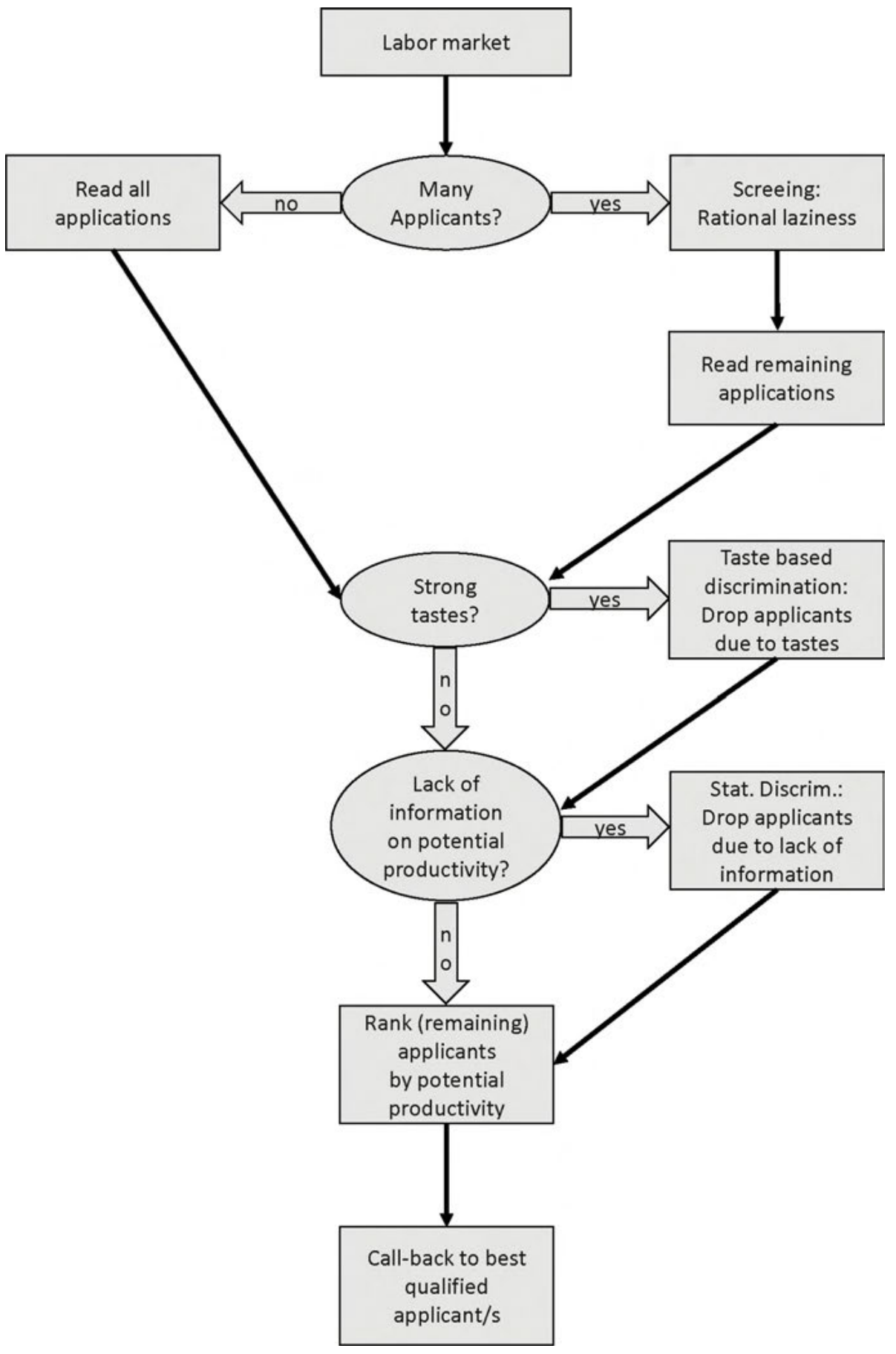

Figure 1: The hiring process an example of Oslo Norway 
I assume an employer who receives few applications (or have screened them to a smaller pool) would read them all (albeit briefly). If the employer does not have strong tastes against some of the applicants he/she would estimate their potential productivity, rank them, and send call-back/s to the best qualified applicant/s. In this case, there is no discrimination involved in this phase of the hiring process.

If the employer has strong tastes (exogenously given) against some applicants he/she might drop them from further consideration (taste-based discrimination). The same would occur if he/she believes customers, or employees in the firm, have strong tastes. The employer would then rank the applicants in the reduced pool, and give call-back/s to the best qualified applicant/s from this pool. In this case, we have a case of taste-based discrimination, where some applicants, who might be among the best qualified/the best qualified, are not considered for the job.

If, however, the employer due to lack of information on individual applicants finds it difficult to estimate their potential productivity, a rational (albeit bounded rational) actor might resort to statistical information on group productivity. Given other options (other applicants with less information uncertainty) a risk-averse employer might drop these applicants from further consideration (statistical discrimination). ${ }^{10}$

The estimation of potential productivity might also occur after employersdue to tastes have reduced the pool of applicants. Thus, statistical discrimination might follow taste-based discrimination. One might also envision hiring processes where the order of these decisions differs from the flow chart: if, for instance, questions of specific tastes occur after an evaluation of the applicants' potential productivity.

A number of studies have tried to identify empirically the social mechanisms involved in discrimination, but in general it is very difficult to distinguish them. As often found in sociology, actors' attitudes might differ from their actions. An US audit study found no discrimination by race when asking employers, but large differences by race when looking at the same employers' hiring decisions (Pager/Quillian 2005). Employers know that discrimination based on ethnic signals, such as names, is not legal. In addition, social processes are complicated and we often would expect more than one social mechanism involved at the same time in most processes (Gambetta 1998). I have tried to delineate the hiring process into different phases, and I have argued we might expect more discrimination in the first part of the process, where employers are likely to be rationally lazy if they have many applications to choose from. I will not be able to document in any stringent way if these decision devices are in fact operating in employers' hiring processes. But I will try to approach an empirical adjudication by reporting from two recent studies.

\footnotetext{
${ }^{10}$ If the information employers rely on is incorrect. this is often called error discrimination. or stereotyped discrimination. since the information might be biased due to stereotypes.
} 


\section{Empirical Adjudication}

I have argued actors' behavior is contingent on their social context and their evaluations of their own opportunities. To understand how biases can be overruled, we need to pay attention to the environment of the individual. This argument should be tested empirically in a rigorous way. Here I will only be able to illustrate my argument. by briefly reporting findings from two empirical studies, which both took place in Oslo in 2011-12 as part of a project on discrimination in the labor market. A Dutch study (Blommaert et al. 2014) documents discrimination of job seekers based only on their names. If names are used for classifying people into in- and out-groups, it would be of interest to know how well-known names are to citizens. I will report findings from an explorative study of names, signaling different nationalities, as an attempt to measure social and geographical distance related to specific countries, or regions of the world. Second, I will present findings from a randomized field experiment testing labor market discrimination in Oslo. We also conducted follow-up interviews with hiring managers (as representative of the employers) in some of these firms.

\section{What's in a name?}

When employers view job applications, the information is usually written (on paper or electronic). Thus, employers see the name of the applicant, and also second generation immigrants often have names that seem foreign to the majority population. It is, however, an open question how well people know foreign names. The first non-western immigrants came to Norway in the late 1960s. Today about 14 percent of the population has immigrant background, but Norway has a short history of immigration from world regions outside Scandinavia and Northern Europe (Brochmann/Kjeldstadli 2008). As a measure of social and geographical distance, we wanted to explore if people are able to associate non-Western foreign names with their nationality. We constructed a list of names associated with the countries of origin of the largest immigrant groups in Norway (44 typical names associated with 11 countries: i.e., 4 country-specific names), and distributed this list to students attending two introduction courses at University of Oslo: one course in Informatics (INF1000) and one course in Sociological methods (SOS1120). There were about 80 students attending each course. We asked the students to identify country of origin for each name, and also (easier) continent (Asia, Africa, etc.). Students were allowed to collaborate, and they worked under time pressure as the survey took place in a 15 minute break at the lectures (Birkelund/Rindsack 2014). There were some minor differences between the two student bodies, but the main findings (averaging 4 name 'hits' within each country) are very similar: 58 percent recognized Chinese names, and only 6-8 percent recognized Lithuanian and Somali names. See figure 2 for more details. 


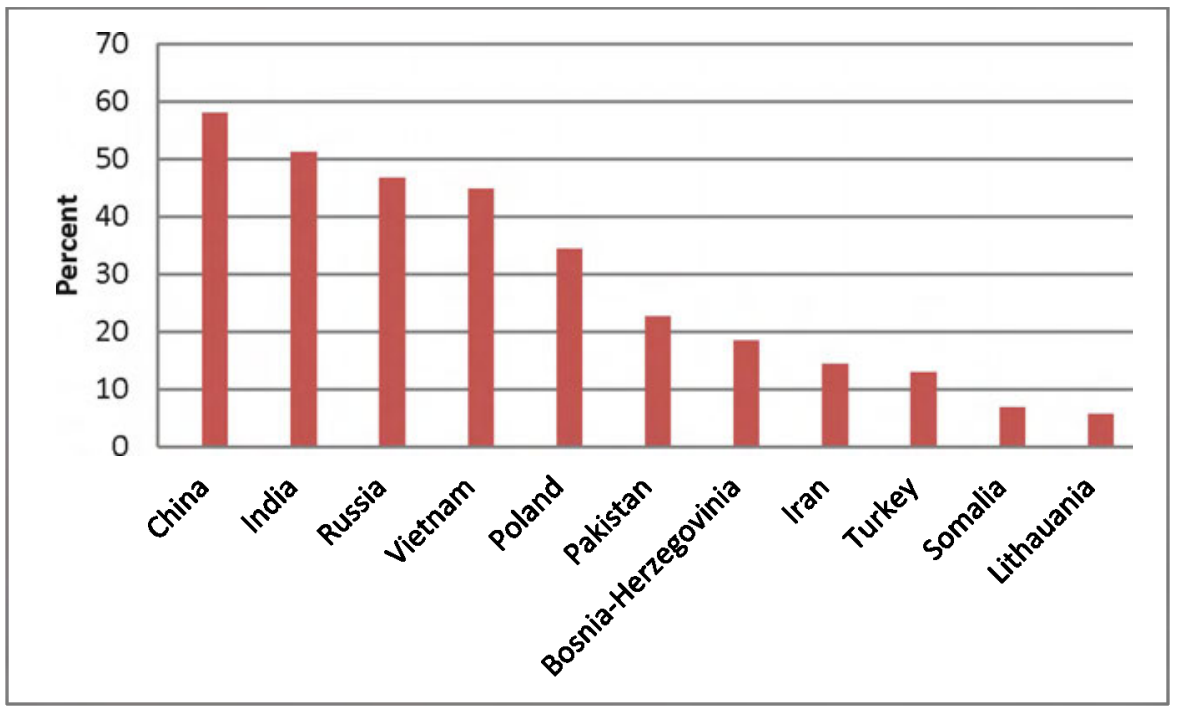

Figure 2: Name-recognition-Norwegian students' identification of nationality associated with names from 11 countries of origin (Source: Birkelund/Rindsack 2014).

The most interesting finding is the lack of knowledge of these names. NorwegianPakistanis are the largest non-Western immigrant group in Norway. and it is interesting to observe the low identification of Pakistani names (less than one in four). We think this is due to the fact that many Pakistani names are Muslim names, commonly found across many countries in the Middle East, Arab countries and Central Asia. ${ }^{11}$ The fact that so few identified Africa as a continent for Somali names supports the idea that Muslim names are associated with Arab countries and Central Asia. ${ }^{12}$

Employers may be more knowledgeable than students. On the other hand, we had the impression that there were in both student bodies - visual minorities present. Thus, we might assume employers a) would either not know about the national identity of foreign names, or, b) if they know the nationality of some of the foreign names, such as Chinese names, their treatment of these applicants would then be dependent upon their tastes, that is, what they associate with these names. Name connotations are typically based on stereotypes and attribution errors, but these may also benefit applicants if the associations are positive,

11 An example is the name Kahn. or Khan. Khan is a surname and title of Central and Western Asian origin, primarily found in Pakistan, India, Afghanistan, Central Asian countries and Bangladesh.

12 In the same way, the (first) names Kristin or Kristian could be Swedish, Norwegian, Danish, German, English (Christian) or from another country where Christian names are common. 
such as: Chinese have strong work ethics. This study illustrates that people do not have specific associations with particular names. thus. a categorization of 'difficult/strange' names into one group (out-group) is likely. This is in line with social psychological research which suggests that one way that people might conserve their limited cognitive resources is by grouping objects into categories and then generate summary beliefs for those groups.

\section{A randomized field experiment}

We then performed a randomized field experiment (correspondence tests) to explore the degree of discrimination against job applicants with Pakistani names in Oslo (see Birkelund et al. 2014). We sent two applications to 289 publically announced vacant jobs. For each job we applied to, we constructed same-sex applications that were similar in all aspects, except for the names of the applicants, where we issued one with a typical Pakistani name and one with a typical Norwegian name. ${ }^{13}$ The applications were given relevant human capital (education and work experience) for each job. We applied for jobs within 6 occupational groups, both unskilled and skilled jobs. It is easily seen from the letter of application and the CVs we sent that the applicants with Pakistani names are second generation immigrants, that is, they were born in Norway to parents who immigrated from Pakistan, and their education was taken at Norwegian educational institutions. Despite similarity in all productivity-relevant characteristics, we found differences in call-back rates showing discrimination against applicants with Pakistani names. Our overall discrimination rate in this study is 1.30 (call-back rate), which is significant. Thus, this gap is not very large, probably reflecting a boosting Norwegian labor market after the 2008 economic crisis, mainly due to oil and gas revenues in the North Sea. See figure 3 for summary of the main findings in our field experiment.

Three interpretations of our findings are likely: A) Employers cannot identify names by their nationality and therefore they group Pakistani applicants together with other 'foreign' names. If many applicants, we would expect these applications to be removed during the first screening. I.e. we would expect strong discrimination based on rational laziness as the main decision device. B) If employers do know about Pakistani names, their decision would be guided by their productivity associations with the Pakistanis as a group. If these associations are positive, we would expect them to favor Pakistanis over other applicants. If these associations are negative, we would expect them to discriminate Pakistani applicants. C) If employers receive few applicants, we would expect them to take a careful look at all, and as our fake candidates have relevant human capital and work experience for the vacant job - we would expect less overall discrimination.

13 We will later expand this study to include more ethnic groups. 


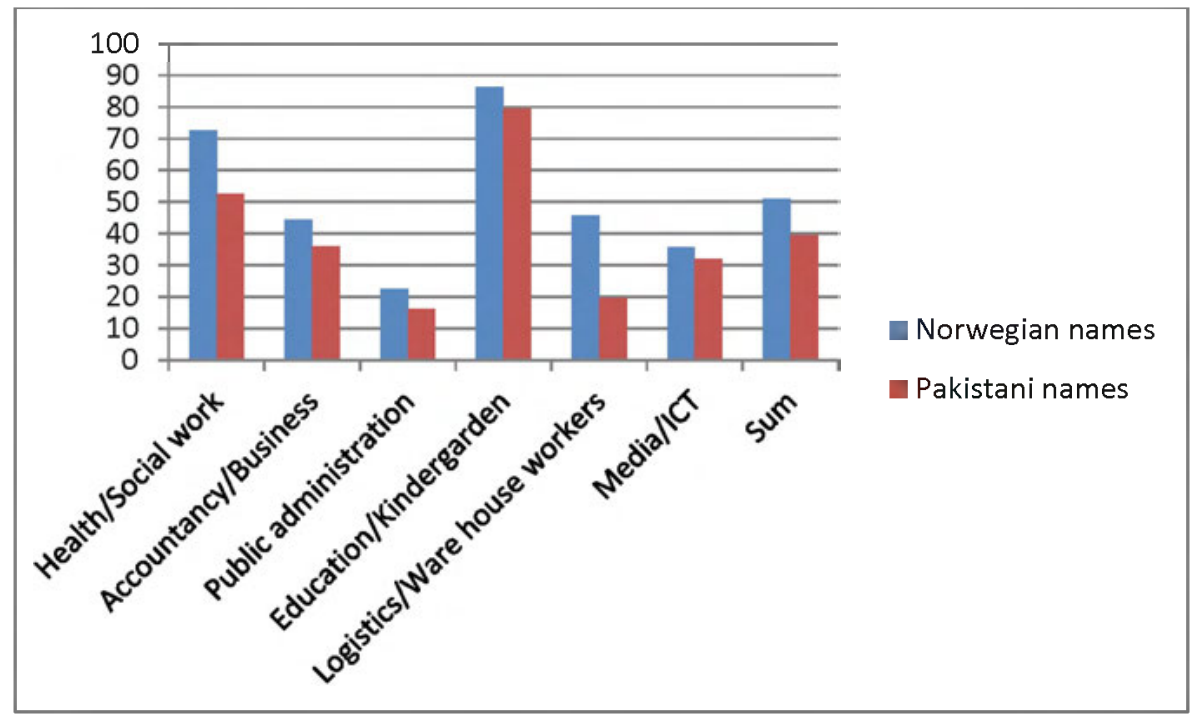

Figure 3: Call-back by ethnicity and occupational group - results from a randomized field experiment. Oslo 2011-2012. (Source: Birkelund et al. 2014)

All of these explanations are plausible, and in interviews with (63 self-selected) employers after the experiment we found some support for the first argument. After we had terminated the field experiment. we sent letters to all participating employers asking them for an interview. 63 employers (out of nearly 300) responded positively: thus this sample is not representative for the group of employers included in the randomized field experiments. Many employers were hiring managers, working in large firms. They knew very well that we were interested in discussing discrimination, thus, they were careful about the impression they gave us: yet, these interviews are interesting data on employers' reflections about their hiring processes. One employer was very specific, saying "First, I always look at names", whereas others would be more careful about admitting to name-based discrimination. ${ }^{14}$

As argued in the introduction, it is interesting to note that employers seem unwilling to distinguish between first and second generation immigrants. In the follow-up interviews, employers talked about immigrants in general, and continued to do so, even after we specifically asked about their view on the life-chances of children of immigrants, born and raised in Norway. Second generation immigrants usually have 'foreign' names, and it seems clear they are lumped together with first generation immigrant applicants, which is a strong argument for outgroup classifications. In the interviews, employers would emphasize language problems, lack of knowledge of the Norwegian society and working life, etc, all

14 We are presently processing and analyzing these interviews. 
characteristics associated with first generation immigrants, and this categorization also comprised second generation immigrants who were born and raised in Norway. It seems clear that employers' unwillingness to distinguish between first and second generation immigrants is related to their out-group definition. based on the job applicants' names. And. I would argue, this classification is the outcome of a rational laziness device: as long as the employers do not need to differentiate between these two groups, they will not do so.

Market matters. We found discrimination to be stronger in unskilled than skilled work. In particular, in warehouse work and truck driving, there was strong discrimination against our fictitious male Pakistani applicants. Here we also found a moderately low response rate (about 45 percent) for our Norwegian applicants, implying that employers in this segment of the labor market have an abundance of applications for these unskilled jobs. It could also be the case that they recruit through networks. If so, these networks would most likely be refer$\mathrm{ral} /$ recommendation networks (since these jobs have been publically announced, which is why we were able to send our fake applications to them). Thus, when the labor supply is large, and/or non-market mechanisms (network) are active, we find strong discrimination. In kindergarten jobs, mostly public sector, the labor supply is tight as there is a shortage of professional kindergarten teachers, resulting in a very high response rate (more than 80 percent). Interestingly, and in line with our market argument, we get a very high response rate for our Pakistani applicants and no significant ethnic differences in call-back in these jobs where the supply of qualified labor is scarce.

The interpretation of the other four occupational groups is less clear. For jobs in the health sector, where the demand for labor also is large (above 60 percent call-back) we find borderline significant discrimination against our Pakistani applicants (significant at 10 percent, but not at the usual 5 percent level). We find the lowest response rate in public administration, and no significant discrimination, probably reflecting the fact that all our applicants are sorted out, unable to compete with other applications (if jobs are attractive, as public sector jobs might be, our applicants would be competing with better qualified applicants). For jobs within media, information and communication technology as well as business administration and accountancy we also find moderately low response rates, and no significant discrimination. If firms in media and ICT are more ethnically heterogeneous than other sectors, this might explain the outcome in this sector (i.e. employers' classification of their in-group might also include (some) minority groups). For accountancy and business economist jobs our interpretation is even less clear. We would assume these firms to be discriminating, since they mostly relate to Norwegian customers, and we would also expect an ethnically homogeneous work force in accountancy firms. A previous study (also correspondence tests) found discrimination within these kinds of jobs (Midtbøen/Rogstad 2012), yet our study did not. 


\section{Conclusion}

Understanding human decision making involves differentiating the mechanisms involved at different stages of the decision making process. As often in complex social processes, we are dealing with a concatenation of mechanisms (Gambetta 1998). First, the macro-to-micro mechanisms define the actor's structural situation, that is, their opportunities. In our case, the (local) labor market and the general time pressure on hiring managers constitute their most relevant situational mechanisms, framing their choices.

Second, we have formulated several action formation mechanisms at the micro level. The opportunity structure, in terms of the number of applications and the time constraints, influences actors' choice of decision device. Each step of the hiring process involves a new decision. In general, employers are expected to operate in a rational-calculating mode (rc-mode). However, when they need to process large amounts of information in a short time period, I expect they are likely to resort to a rational laziness mechanism. Thus, rc-mode is replaced by as-mode, before employers switch back to rc-mode. The decision to invoke the laziness mechanism is rational since it reduces the work load.

We have here addressed the first stage of the hiring process, to understand who gets a call-back for an interview. But later in the hiring process some of the applicants are interviewed, and then employers may draw on a number of more subtle evaluations of the applicants, involving personal perceptions, their so-called 'gut' feeling, previous experiences, etc. (Midtbøen/Rogstad 2012).

We do not need to assume all employers activate these scripts: it suffices to assume that some employers do so. The outcomes of these individual decisions, made every day by employers/hiring managers, generate macro-patterns of group differentiated employment rates. In addition to simple aggregation we might also outline more complex and dynamic transformative mechanisms. One such mechanism might be the discouraged worker effect, where job applicants of particular groups register that members of their group are given fewer job opportunities. As a response to actual and perceived discrimination, they might be discouraged from sending job applications, which would naturally sustain their unemployment status.

Human beings are cognitively lazy. If we think our opportunities are good enough we do not consider all possible alternatives: we limit our search to a smaller sample. If employers have enough qualified native applicants to choose from, they do not have to differentiate between first and second generation immigrants - to find out who has relevant education, who knows Norwegian, etc. When time is limited, supply abundant, and decisions have to be made, it makes sense to be cognitively lazy and choose an easy way out.

I have tried to develop a new concept, rational laziness, as an attempt to understand why employers did not differentiate between first and second generation immigrants. Understanding discrimination is crucial in order to eventually create a fair labor market. Existing economic theories of discrimination, such as taste-based discrimination and statistical discrimination, are abstract models of employers' decision making. I have suggested a more nuanced model of de- 
cision making to help us understand the first part of employers' hiring process. in particular the screening of the job applicants. This concept builds on and extends Herbert Simon's decision making model. by including information on non-cognitive in- and out-group classifications. Employers' choice of decision devices is, I argue, dependent upon their opportunity structure. This argument partly covers the same evaluations as Simon's argument about satisficing strategies in decision making, but adds the involvement of non-cognitive decision devices, such as automatic in-/out-group classifications. When time is limited and supply abundant, employers are likely to be rationally lazy and apply some sort of heuristic to screen large numbers of job applications. If supply is limited (i.e., few applications), employers are likely to scrutinize each application more carefully. The actor is cognitively lazy only after first evaluating if this is a rational strategy to choose. This also means that non-cognitive - and, as documented in implicit association tests, usually biased - decision devices are contingent on a cognitive decision making process, where the actor's perception of his/her opportunities is a vital parameter. Thus, choice of action is contingent on the employer's evaluations of the available time for the task at hand and the market position of the firm.

The concept of rational laziness is meant as one decision device among others. To test these mechanisms empirically is very difficult, and I have only given circumstantial evidence here. The argument hinges on the volume of the job task, and one way to check this would be to look at the number of applications for each vacant job. Labor market statistics do not have this information, so I have tried to provide some circumstantial evidence for this argument. First, a majority of the students in two different study programs at the University of Oslo were unable to recognize names of non-Western immigrants. This provides indirect evidence of out-group classification of people with non-Western names as foreigners and strangers. Second, a recent field experiment showed less discrimination in jobs with scarce labor supply, which indicates employers rely on a rational decision device when they receive few applications. This study also documented more discrimination in unskilled jobs, where we might expect the labor supply to be plentiful. In interviews employers also indicated that they do screen job applicants on the basis of their names.

The concept of rational laziness might also be useful for understanding other decision making processes. Why did I choose higher education without considering if I would get a job afterwards? And why do I always buy the same type of toothpaste without considering if there are better toothpastes in the market? Because human beings are lazy. If we think our opportunities are good enough we do not consider all possible alternatives; we limit our search to a smaller sample, and sometimes we do not think when we choose, since we have developed a habit (as when I 'choose' toothpaste). I did not worry about the long-term consequences of choosing sociology, and it turned out I was right, I did get a job. I also think it would take too much time to evaluate all toothpastes in the market, so I do not bother checking, and I would guess toothpastes are fairly similar anyway. I might be wrong, of course. But when time is limited, supply 
abundant, and decisions have to be made. it makes sense to be cognitively lazy and choose an easy way out.

We are often rationally lazy, involving non-cognitive decision devices, but certainly not all the time. In situations where the outcome of a decision is particularly important, we should expect human beings to involve several decision devices, including also cognitive laziness. For choosing education, or finding a partner, it would be particularly important to validate one's choice, using more than one decision device.

The argument advanced here seems pessimistic, since it is contextual factors (market logic), i.e... employers' opportunity structure, as revealed in the volume of the task, that influences job opportunities of immigrants (and second generation immigrants). However, employers are learning actors, and in time they might include minority applicants in their preferred in-group if they have good experiences with representatives of the relevant minority group. Non-Western immigrants have a short history in many European countries, and the majority population is unlikely to know a lot about these groups. It is therefore no reason to expect similar attitudes and stereotypes towards the new immigrants as the stereotypes against blacks found in the US, where studies show strong attitudinal resilience (Pager/Karafin 2009). Since immigrants increasingly are integrated in the labor market, this argument also means that the expectations given above on employers' behavior portray a more black and white picture than we would find in real life. That is, the mechanism related to rational laziness would be the same: we would still expect employers to be lazy if they have enough qualified applicants from their preferred in-group, but their definition of who belongs to their preferred in-group might be more inclusive, in which case the outcome of their decision making would be more open.

\section{Bibliography}

Arai, M./P. Skogman Thoursie (2009), Renouncing Personal Names: An Empirical Examination of Surname Change and Earnings, in: Journal of Labor Economcis $27,127-147$

Arrow, K. J. (1972), Models of Job Discrimination, in: Pascal, A. H. (ed.), Racial Discrimination in Economic Life, New York, 83-102

Baragh, J. A./T. L. Chartrand (1999), The Unbearable Automacy of Being, in: American Psychologist 54, 462-479

Baumeister, R. F./E. Bratslavsky/M. Muraven/D. M. Tice (1998), Ego Depletion: Is the Active Self a Limited Resource?, in: Journal of Personality and Social Psychology $74,1252-1265$

Becker, G. (1971[1957]), The Economics of Discrimination, $2^{\text {nd }}$ edition, Chicago

Birkelund, G. E. (2010), Die Kontextualisierung von Akteuren und ihren Präferenzen, in: Kron, T./T. Grund (eds.), Die Analytische Soziologie in der Diskussion, Wiesbaden, $153-164$

-/J. Rogstad/K. Heggebø/T. Mogstad Aspøy/H. Fischer Bjelland (2014), Diskriminering i arbeidslivet. Resultater fra randomiserte felteksperiment i Oslo, Stavanger, Bergen og Trondheim, in: Sosiologisk tidsskrift 22, 352-382 
-/O. T. Rindsack (2014), Дискриминация по имени: опыт исследования на норвежском рынке труда, in: Sociologiceskie issledovaniâ 12, 38-40

Blommaert, L./M. Coenders/F. van Tubergen (2014). Discrimination of ArabicNamed Applicants in the Netherlands: An Internet-Based Field Experiment Examining Different Phases in Online Recruitment Procedures, in: Social Forces 92, $957-982$

Boudon, R. (1989), Subjective Rationality and the Explanation of Social Behavior, in: Rationality and Society 1, 173-196

Brochmann, G./K. Kjeldstadli (2008), A History of Immigration. The Case of Norway $900-2000$, Oslo

Chapin, A./M. Dean/D. Martin (2011), Search and Satisficing, in: American Econonic Review 101, 2899-2922

Coleman, J. S. (1990), Foundations of Social Theory, Harvard

Dovidio, J. R./S. L. Gaertner (2000), Aversive Racism and Selection Decisions: 1989 1999, in: Psychological Science 11, 315-319

Elster, J. (1985), Sour Grapes: Strudies in the Subversion of Rationality, Cambridge

- (2007), Explaining Social Behavior: More Nuts and Bolts for the Social Sciences, Cambridge

England, P. (1992), Comparable Worth: Theories and Evidence, Hawthorne

Esser, H. (2001), Soziologie. Spezielle Grundlagen. Band 6: Sinn und Kultur, Frankfurt

Fiske, S. T. (2000), Stereotyping, Prejudge, and Discrimination at the Seam between the Centuries: Evolution, Culture, Mind, and Brain, in: European Journal of Social Psychology 30, 299-322

- S. E. Taylor (1984), Social Cognition, New York

Foschi, M. (2000), Double Standards for Competence: Theory and Research, in: Annual Review of Sociology 26, 21-42

Gaertner, S. L./J. R. Dovidio (2005), Understanding and Addressing Contemporary Racism: From Aversive Racism to the Common Ingroup Identity Model, in: Journal of Social Issues 61, 615639

Gambetta, D. (1998), Concatenations of Mechanisms, in: Hedström, P./R. Swedberg (eds.), Social Mechanisms, Cambridge, 102-124

Goldstein, D. G. (2009), Heuristics, in: Hedström, P./P. Bearman (eds.), The Oxford Handbook of Analytical Sociology, Oxford, 140-167

Hedström, P. (2005), Dissecting the Social. On the Principles of Analytical Sociology, Cambridge

- R. Swedberg (1998) (eds.), Social Mechanisms, Cambridge

Hernes, G. (1998), Real Virtuality, in: Hedström, P./R. Swedberg (eds.), Social Mechanisms, Cambridge, 74-101

Hutchinson, J. M. C./G. Gigerenzer (2005), Simple Heuristics and Rules of Thumb: Where Psychologists and Behavioral Biologists Might Meet, in: Behavioral Processes $69,97-124$

Jost, J. T./L. A. Rudman/I. V. Blair/D. R. Carney/N. Dasgupta/J. Glaser/C. D. Hardin (2009), The Existence of Implicit Bias Is beyond Reasonable Doubt: A Refutation of Ideological and Methodological Objections and Executive Summary of Ten Studies That No Manager Should Ignore, in: Research in Organizational Behavior 29, 39-69

Kahneman, D. (2003), Maps of Rationality: Psychology for Behavioral Economic, in: The American Economic Review 93, 1449-1475

- (2011), Thinking, Fast and Slow, London 
Kroneberg. C. (2014). Frames, Scripts, and Variable Rationality: An Integrative Theory of Action, in: Manzo, G. (ed.), Analytical Sociology, Actions and Networks, West Sussex, 97-123

Manzo, G. (2014) (ed.), Analytical Sociology, Actions and Networks, West Sussex

Midtbøen, A. A./J. Rogstad (2012), Diskrimineringens omfang og årsaker. Etniske minoriteters tilgang til norsk arbeidsliv, ISF-rapport 1, Oslo

OECD (2013), Discrimination against Immigrants-Measurement, Incidence and Policy Instruments, in: International Migration Outlook 2013, URL: http://dx.doi.org/ 10.1787/migr_outlook-2013-7-en

Pager, D./D. Karafin (2009), Bayesian Bigot? Discrimination, Stereotypes, and Employer Decision Making, in: The ANNALS of the American Academy of Political and Social Science 621, 70-93

-/L. Quillian (2005), Walking the Talk? What Employers Say versus What They Do, in: American Sociological Review 70, 355-380

Petersen, T./I. Saporta (2004), The Opportunity Structure for Discrimination, in: American Journal of Sociology 109, 852-901

- (2009), Opportunities, in: Hedström, P./P. Bearman (eds.), The Oxford Handbook of Analytical Sociology, Oxford, 115-139

Phelps, E. S. (1972), The Statistical Theory of Racism and Sexism, in: American Economic Review 62, 659-661

Purkiss, S./L. Segrest/P. L. Perrewe/T. L. Gillespie/B. T. Mayes/G. R. Ferris (2006), Implicit Sources of Bias in Employment Interview Judgements and Decisions, in: Organizational Behavior and Human Decision Progresses 101, 152-167

Ridgeway, S. (1991), The Social Construction of Status Value, in: Social Forces 70, $367-386$

Rooth, D.-O. (2010), Automatic Associations and Discrimination in Hiring: Real World Evidence, in: Labour Economics 17, 523-534

Simon, H. (1955), A Behavioral Model of Rational Choice, in: The Quarterly Journal of Economics 69, 99-118

- (1959), Theories of Decision-Making in Economics and Behavioral Science, in: The American Economic Review 49, 253-283

Stevens, L. E./S. T. Fiske (1995), Motivation and Cognition in Social Life: A Social Survival Perspective, in: Social Cognition 13, 189 214

Tajfel, H./M. G. Billig/R. P. Bundy/C. Flament (1971), Social Categorization and Intergroup Behavior, in: European Journal of Social Psychology 1, 149-178 
Brought to you by | University of Oslo Norway 